\title{
Addition of Carrot Pomace to Increase the Nutritional and Rheological Properties of Traditional Cake
}

\author{
Shalini Semwal ${ }^{1}$, Neha Chaudhary ${ }^{2}$, Sachin Karoulia ${ }^{3}$ \\ ${ }^{1,2}$ Baba Fareed Institute of Science and Research Technology, Dehradun, India
}

\begin{abstract}
Carrot is one of the important root vegetables rich in bioactive compounds like carotenoids and dietary fibres with appreciable levels of several other functional components having significant health-promoting properties. The consumption of carrot and its products is increasing steadily due to its recognition as an important source of natural antioxidants having anticarcinogenic activity. Carrot pomace can be utilized in regular course as a by-product by the means of fortification, supplementation of products like cake, bread, biscuits and preparation of several types of functional products, as it contain about 50\% of $\beta$-carotene it has significant nutritional value. The insoluble fibres, cellulose and hemicellulose, constitute the greatest portion (50\%to 92\%) of the total dietary fibre with a very small amount of lignin (4\%). The fibre composition of carrot pomace can differ from whole carrot depending on the processing method. Wheat flour is more nutritious in comparison of maida. The present review highlights the nutritional composition, health promoting phytonutrients, functional properties, products development and by-products utilization of carrot and carrot pomace along with their potential application.
\end{abstract}

Keywords: Carotenoids, Dietary fibre, Antioxidants, Pomace, Phytonutrients.

\section{Introduction}

Cakes are popular and are associated in the consumer's mind with a delicious sponge product with desired organoleptic characteristics (Matsakidor et al.2010). Cake quality is determined by three major factors: viz ; appropriates of ingredients for the specific type of cake being made a properly balanced formula and the optimum mixing and baking process (Cauvain and young 2006). Starch gelatinization and protein denaturation together with carbondi-oxide with a fine homogenous moist crumb (Sahi et al.2003; Cauvain and young 2006). Cake flour is low ash and low protein content produced for best cake quality by milling technology of soft as well as hard wheat that is free of bran \& wheat germ. Soft wheat flour are usually weak flour and low in water absorption (Edmund et al.2008; AlDmoor, 2012). The best cakes are obtained from a lowprotein flour $(7-9 \%)$ to give soft cakes. The general composition for typical cake flour are water $14.5 \%$, proteins $7-8 \%$, starch $72-74 \%$, sugars $1-2 \%$ lipids $0.4-0.6 \%$ cellulose $0.1 \%$ and minerals $0.2-0.5 \%$. Extraction rate for cake flour production is $50 \%$ mostly are applied in flour milling (Edmund et al., 2008; AlDmoor, 2012).

Not only wheat flour but also other flour types have been investigating for developing cakes of lower cost \& better quality in terms of consumer acceptance (Turbai et al.). The nutrition value of wheat is extremely important as it takes an important place among the few crop species being extensively grown as staple food (Lindsay 2002, Welch and Graham 2002). They have no enzyme activity, but they have a function in the formation of dough as they retain gas, producing spongy baked products (Belderok et.al 2000). Wheat flour approximately consists of $72 \%$ carbohydrate, 8 to $13 \%$ moisture, $2.5 \%$ sugar and $1.5 \%$ fat, $1.0 \%$ soluble protein and $0.5 \%$ minerals salt (Oberoi et.al,2007). Wheat also lowers the level of esterogen in the blood which reduces the risk of breast and prostate cancers (John et al.2006).
Enhancing substances (e.g. ascorbic acid, S-containing amino acids, etc) that promote micronutrient bioavailability or decreasing antinutrient substances (e.g. phytate, polyphenolics, etc) that inhibit micronutrient bioavailability, are both options that could be pursued in breeding programs (Welch 2002; Welch and Graham 2004; Welch 2005).

Carrots (Daucus carota L.) are more than a versatile orange vegetable. Original carrots were purple and yellow, initially described in the 10th century in Iran and northern Arabia (Simon2000). Carrots do not supply a significant amount of calories to the human diet, but do supply nutrition in the form of phytochemicals, such as carotenoids, anthocyanins, and other phenolic compounds. Nutrient content of carrots can vary with cultivar (Nicolle and others 2004), season (Horvitz and others 2004), environmental conditions (Rosenfeld and others 1998), and maturity (Phan and Hsu 1973).Carrot pomace is a byproduct obtained during carrot juice processing. The juice yield in carrots is only $60-70 \%$, and even up to $80 \%$ of carotene may be lost with left over carrot pomace (Bohmet al., 1999). Dried carrot pomace has carotene and ascorbic acid in the range of 9.87 to $11.57 \mathrm{mg}$ and 13.53 to $22.95 \mathrm{mg}$ per $100 \mathrm{~g}$, respectively (Upadhyay et al., 2008). Carrots contribute significantly to dietary vitaminA intake through $\alpha$ - and $\beta$-carotene and modestly to other nutrients. The insoluble fibres, cellulose and hemicellulose, constitute the greatest portion (50\% to 92\%) of the total dietary fibre with a very small amount of lignin (4\%). The fibre composition of carrot pomace can differ from whole carrot depending on the processing method. Carrot pomace made from carrot peels had a reduced insoluble to soluble dietary fibre ratio when blanched before drying (Chantaro and others 2007), increasing its perceived quality as a functional fibre for adding to other foods. The water retention and swelling capacities of carrot pomace were relatively high compared to other agricultural byproducts such as apple, pear, and orange pomace (Chantaro and others 2007). Carotenoids are responsible 


\section{International Journal of Science and Research (IJSR) \\ ISSN (Online): 2319-7064}

Index Copernicus Value (2013): 6.14 | Impact Factor (2015): 6.391

for the yellow, orange, and red colors of carrots, while anthocyanins, a class of polyphenolic compounds, are responsible for the color of purple carrots. All of these pigments have been studied for their health benefits, including protection from certain cancers and cardiovascular disease, and consumer interest in natural whole foods rich in these compounds, often referred to as "functional foods," is growing (Hasler and Brown 2009).

\section{Materials and Methods}

Wheat flour, maida, shortening, dried pomace of carrots, baking powder, spent carrots, egg, butter and powdered sugar were procured from the local market of Dehradun.

The cake shall be suitably baked with due allowance for heat penetration of the edges. It shall not show signs of under baking or over baking. Cake shall be moist, uniform in texture with even distribution of added ingredients like peels and fruits and shall be spongy. It shall have the color, texture, flavor and aroma characteristic of typical well-baked cakes and shall be free from any evidence of rancidity or other objectionable tastes, insect or fungus and mould infestation.

Characteristics as specified by PFA 1955

\begin{tabular}{|c|c|c|}
\hline S. No & Characteristics & Cake \\
\hline 1. & Moisture ,present by mass, Max & $15-25$ \\
\hline 2. & $\begin{array}{c}\text { Acid insoluble ash (on as is basis), percent by } \\
\text { mass, Max }\end{array}$ & 0.1 \\
\hline 3. & $\begin{array}{c}\text { Acidity of extracted fat (as oleic acid ), } \\
\text { percent by mass, Max }\end{array}$ & 1.0 \\
\hline
\end{tabular}

Now that the act is taken over by new FSSAI act 2006 still the bakery manufacturers should be aware of the guidelines and standards given in this PFA act 1954 - PFA rules 1955.

\section{Raw material}

(Wheat flour, baking powder, spent carrot, egg, butter, powdered sugar)

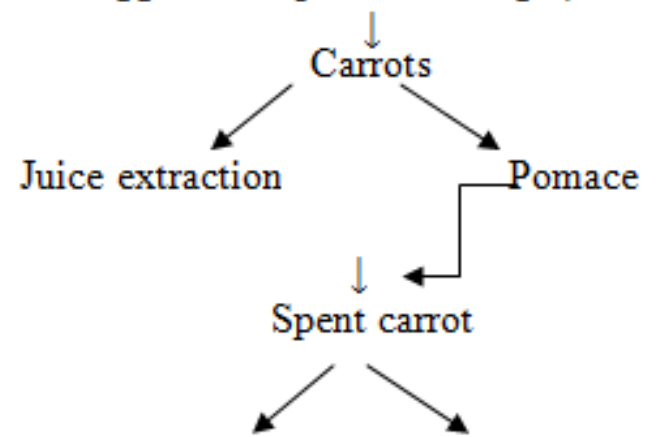

Sun dried

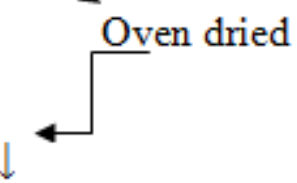

Dried spent carrots

Grinding of dried spent carrot
Sieving of flour and dried spent carrot<smiles>[13CH2][13CH3]</smiles>

Granules

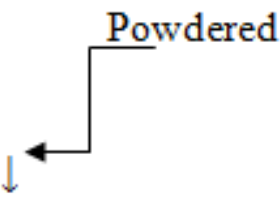

Weighing of raw materials

Preheating of Oven $\left(200^{\circ} \mathrm{C}\right.$ for $\left.20 \mathrm{~min}\right)$

Beating of sugar and melted butter

Addition of egg

Beating (10 min)

Addition of wheat flour, baking powder and spent carrot

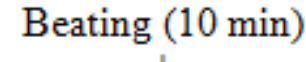

Greasing of baking mould

Pouring of cake batter

Settling of batter

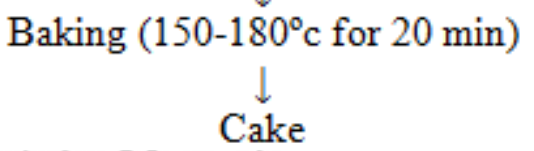

Figure 1: Flow chart showing preparation of Cake

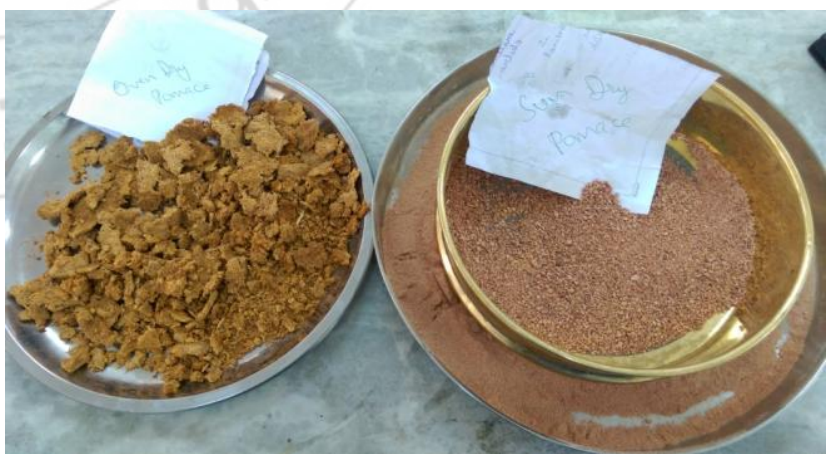

a.) Dried pomace by oven dry(orange color) and sun dry(red color) methods 


\section{International Journal of Science and Research (IJSR) \\ ISSN (Online): 2319-7064}

Index Copernicus Value (2013): 6.14 | Impact Factor (2015): 6.391

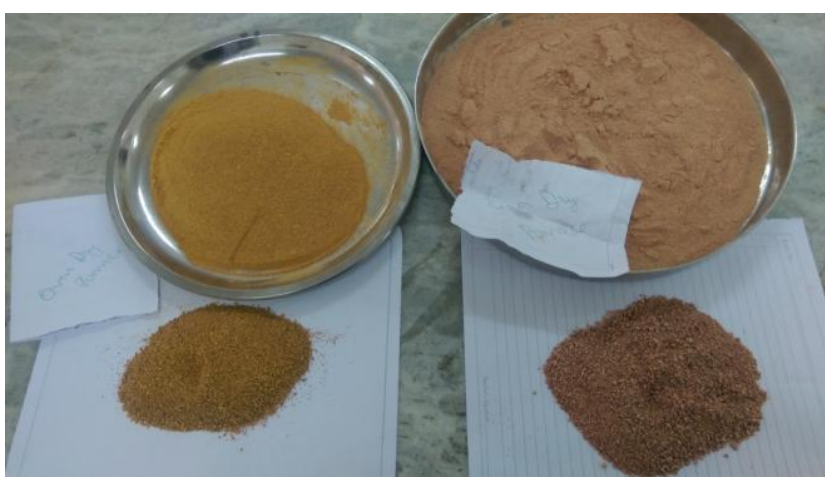

b.) Dried pomace is categorized in two forms:- i. granules ii. powdered

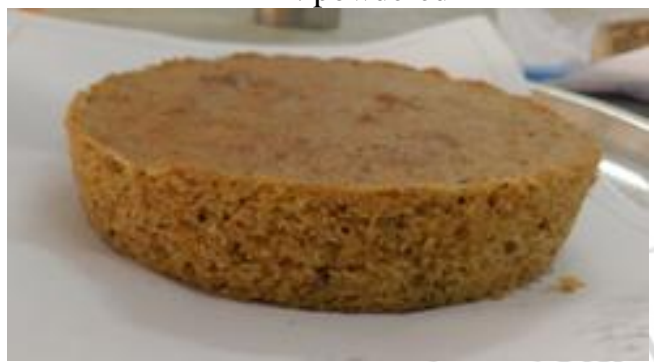

c.) Spent carrot cake

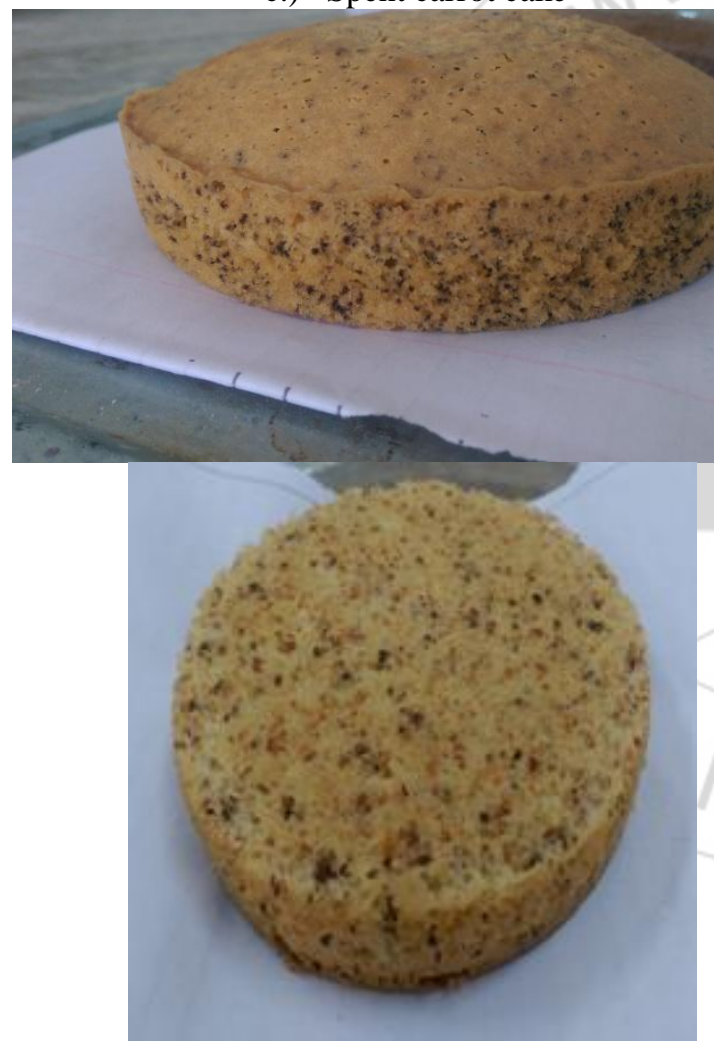

d.) Cake prepared by using spent carrots in granule form

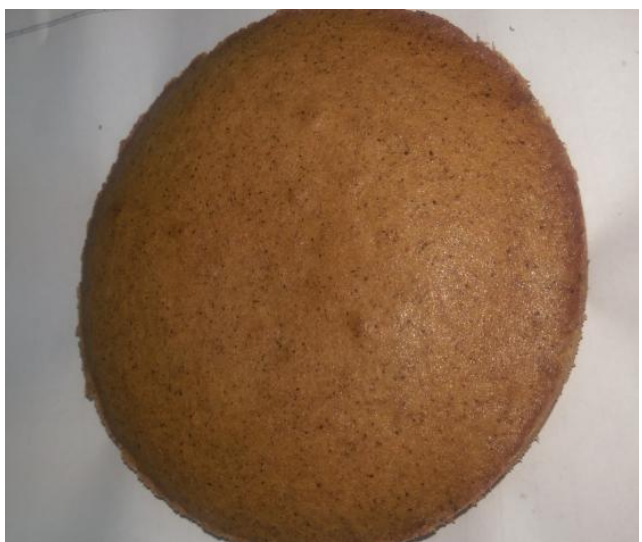

e.) Cake prepared by using spent carrots in powdered form Figure 2

\section{Preparation of Cake}

The ingredients Wheat flour, spent carrots, eggs, butter, baking powder and sugar were bought from the local market of Dehradun. All the raw material was properly measured according to the ratio required in cake. The process of sieving was done through fine sieves for wheat flour \& dried spent carrots to eliminate the dirt, dust and such unwanted particles. Meanwhile the oven is preheated at $200^{\circ} \mathrm{C}$ for 20 min. The weighed sugar and melted butter were beaten properly using beater for $10 \mathrm{~min}$. The egg was added and beating of the batter was continued for 10mins by using beater. Further addition of wheat flour, dried spent carrot, baking powder and again proper beating was done for 10 min. The beating process should be done in such a way that there should be no presences of bubbles, faster the beating process smoother the batter of the cake obtained. Then batter was poured in greased baking mould and even settling was done by using spreader. After the settling of batter it was baked in preheated oven at $150-180^{\circ} \mathrm{C}$ for $20 \mathrm{~min}$.

\section{PFA Guidelines}

1) This Indian Standard was adopted by the Indian Standards Institution on 30 January 1981, after the draft finalized by the Bakery and Confectionery Industry Sectional Committee had been approved by the Agricultural and Food Products Division Council.

2) Cake is a baked food which contains many important nutrients such as proteins, carbohydrates, fats and some minerals. It may also he enriched with vitamins.

3) Batter for the cake is usually prepared from a mixture essentially containing MAIDA, sugar and eggs in case of sponge cake; and MAIDA, sugar, fat, eggs and other ingredients in case of other cakes depending upon the type of cake to the prepared. Various methods are used for mixing the ingredient. The batter of requisite mass is put into cake tins and baked in an oven at suitable temperature for suitable time.

4) In the preparation of this standard, due consideration has been given to the Prevention of Food Adulteration Act, 1954 and the Rules framed there under. Due consideration has also been given to the Standards of Weights and Measures (Packaged Commodities) Rules, 1977. This standard is, however, subject to the restrictions imposed under these, wherever applicable. 


\section{International Journal of Science and Research (IJSR) \\ ISSN (Online): 2319-7064 \\ Index Copernicus Value (2013): 6.14 | Impact Factor (2015): 6.391}

5) For the purpose of deciding whether a particular requirement of this standard is complied with, the final value, observed or calculated, expressing the result of a test or analysis, shall be rounded off in accordance with IS : 2-1960*. The number of significant places retained in the rounded off, value should be the same as that of the specified value in this standard.

Sensory Evaluation: 9 point hedonic scale

\begin{tabular}{|c|c|c|c|c|c|}
\hline Parameter & Color & Texture & Flavor & Taste & $\begin{array}{c}\text { Overall } \\
\text { acceptability }\end{array}$ \\
\hline Panelist 1 & 7 & 6 & 8 & 7 & 7 \\
\hline Panelist 2 & 8 & 7 & 8 & 7 & 7.5 \\
\hline Panelist 3 & 8 & 7.5 & 7 & 7 & 7.3 \\
\hline Panelist 4 & 8 & 6 & 6 & 7 & 6.7 \\
\hline Panelist 5 & 8 & 7 & 7 & 6 & 7 \\
\hline Panelist 6 & 8 & 7 & 7 & 7 & 7.2 \\
\hline Panelist 7 & 8 & 7 & 8 & 7 & 7.5 \\
\hline Panelist 8 & 8 & 7 & 8 & 8 & 7.7 \\
\hline Panelist 9 & 7 & 6 & 8 & 7 & 7 \\
\hline Panelist 10 & 8 & 7 & 7 & 8.5 & 7.6 \\
\hline Overall acceptability & 7.8 & 6.7 & 7.4 & 7.1 & - \\
\hline
\end{tabular}

\section{Color}

The overall acceptability obtained for the parameter was 7.8 which was more than the acceptability level that is 5 . The acceptability of the product was obtained by sensory evaluation which was done by 10 semi trained penalists on the basis of 9 point hedonic scale.

\section{Texture}

The overall acceptability obtained for the parameter was 6.7 which was more than the acceptability level that is 5 . The acceptability of the product was obtained by sensory evaluation which was done by 10 semi trained penalists on the basis of 9 point hedonic scale.

\section{Flavor}

The overall acceptability obtained for the parameter was 7.4 which was more than the acceptability level that is 5 . The acceptability of the product was obtained by sensory evaluation which was done by 10 semi trained penalists on the basis of 9 point hedonic scale.

\section{Taste}

The overall acceptability obtained for the parameter was 7.1 which was more than the acceptability level that is 5 . The acceptability of the product was obtained by sensory evaluation which was done by 10 semi trained penalists on the basis of 9 point hedonic scale.

Table 1: Effect of dreid pomace (dp) sieve size on sensory attributes of spent carrot cake

\begin{tabular}{|c|c|c|c|c|}
\hline Sieve size (mics) & Appearance & Texture & Flavor & $\begin{array}{c}\text { Overall } \\
\text { acceptability }\end{array}$ \\
\hline 250 & 8.00 & 8.00 & 8.33 & 8.11 \\
\hline 425 & 7.86 & 7.58 & 7.83 & 7.75 \\
\hline 500 & 7.66 & 6.92 & 7.66 & 7.41 \\
\hline
\end{tabular}

The sensory scores for appearance, flavor and texture as affected by dried pomace are presented in table no.1. The scores for all sensory attributes decreased with increase in sieve size from 250-500 mics. The scores for flavor also decreased with increase in sieve size as a result of the granules getting stuck to the teeth as that of the smaller size. This indicates that the product made from the smaller sieve size is better in comparison to the larger sieve size. The overall acceptability score was found to be highest (8.11) for the sample with 250 sieve size. Size reduction is used in processing to control the textural or rheological properties of foods and to improve efficiency of mixing and heat transfer. The texture of many foods is controlled by conditions used during size reduction of ingredients. There is also indirect effect on aroma and flavor of some foods.

Table 2: Effect of method of cooking on tensile strength of spent carrot cake

\begin{tabular}{|c|c|c|c|c|}
\hline Cooking method & Appearance & Texture & Flavor & $\begin{array}{c}\text { Overall } \\
\text { acceptability }\end{array}$ \\
\hline Open pan, 20 min & 8.08 & 7.33 & 7.92 & 7.78 \\
\hline Closed pan, 10 min & 7.66 & 7.66 & 7.42 & 7.58 \\
\hline
\end{tabular}

The method of cooking of dried pomace did not have significant effect on appearance, texture, flavor and overall acceptability scores of spent carrot cake. The cooking of dried pomace in opnen pan (OP) required longer time (20min) for optimum softening as compared to closed pan cooking (10 min). It obtained higher scores for attributes of appearance and flavor as compared to closed pan (CP) cooking. There was no significant difference in the texture scores of the cooking methods, even though the texture score was higher for closed pan cooking than open pan. Also, there was no significant difference in the overall acceptability scores of the cooking methods. Spent carrot cake samples prepared by open pan cooking method obtained higher overall acceptability scores as compared to closed pan cooking.

Table 3: Effect of varying levels of pomace on sensory attributes of spent carrot cake

\begin{tabular}{|c|c|c|c|c|}
\hline $\begin{array}{c}\text { Pomace } \\
\text { Level \% }\end{array}$ & Appearance & Texture & Flavor & $\begin{array}{c}\text { Overall } \\
\text { acceptability }\end{array}$ \\
\hline 5 & 8.00 & 7.25 & 7.16 & 7.47 \\
\hline 10 & 8.16 & 8.17 & 7.50 & 7.94 \\
\hline 15 & 8.50 & 8.75 & 8.83 & 8.69 \\
\hline 20 & 7.83 & 8.15 & 8.58 & 8.19 \\
\hline 25 & 7.33 & 8.00 & 7.92 & 7.75 \\
\hline 30 & 6.83 & 8.00 & 7.33 & 7.39 \\
\hline 35 & 6.67 & 7.67 & 7.00 & 7.11 \\
\hline 40 & 6.50 & 7.50 & 6.80 & 6.97 \\
\hline
\end{tabular}

There was an increase in firmness/ hardness of cakes with increase in pomace content. At pomace level of more 25 percent texture became quite hard whereas at pomace level of less than 15 percent, texture was soft and could not retain its shape. Therefore, levels lower than 15 percent were not considered desirable for good cake formation. The spent carrot cake samples containg different levels of pomace were found to have significant effect on flavor attribute. The scores increased upto 15 percent pomace incorporation and obtained highest value among various levels of pomace incorporation. This may be due to the fact that carrot flavor was prominent upto 15 percent pomace addition whereas typical cooked pomace flavor dominated above this level. Increase in pomace increased sweetness of the product which was not liked by the sensory panels. The spent carrot cake sample containing 15 percent pomace had balanced

\section{Volume 5 Issue 5, May 2016}




\section{International Journal of Science and Research (IJSR) \\ ISSN (Online): 2319-7064 \\ Index Copernicus Value (2013): 6.14 | Impact Factor (2015): 6.391}

flavor of both the major ingredients. i.e. wheat flour and pomace . Probably because of these reasons, spent carrot cake with 15 percent pomace was found to have highest scores for overall acceptability (8.69). Therefore 15 percent level of pomace was considered optimal.

Table 4: Effect of sugar content on sensory attributes of spent carrot cake

\begin{tabular}{|c|c|c|c|c|}
\hline $\begin{array}{c}\text { Sugar content } \\
(\%)\end{array}$ & Appearance & Texture & Flavor & $\begin{array}{c}\text { Overall } \\
\text { acceptability }\end{array}$ \\
\hline 20 & 8.16 & 7.66 & 7.92 & 7.91 \\
\hline 22.5 & 8.16 & 7.83 & 8.00 & 8.00 \\
\hline 25 & 8.16 & 7.50 & 7.33 & 7.66 \\
\hline
\end{tabular}

There was no difference in the appearance scores of spent carrot cake containing different levels of sugar in the above table. This may be due to the reason that increased sugar level from 20-25 percent did not apparently affect the color and brightness of the samples. Also, there was no significant difference in the texture scores of spent carrot cake containing different levels of sugar. However, the highest score of 7.83 for texture 22.5 percent sugar. The score was lowest for sample containing 25 percent sugar. The reason could be attributed to the fact that higher sugar content released more water from the sample and therefore, required longer heating to everyone the moisture completely for proper cake formation resulting in hard texture of spent carrot cake. There were no significant differences in the flavor scores of spent carrot cakes samples containing sugar levels from 20-25 percent. The sample containing 22.5 percent sugar scored highest for the attribute of flavor amongst the three sugar levels studied, following by 20-25 percent sugar. The 25 percent sugar level was found to have lowest flavor scores were found to be highest (8.0) for the samples with 22.5 percent sugar content. Sugar level of 22.5 percent was therefore, considered to be optimum.

\section{References}

[1] Bohm V, Otto K, Weissleder F (1999). Yield of juice and carotenoids of the carrot juice production, In: Symposium Jena-Thuringen,Germany, pp. 115-119.

[2] Bryant JD, McCord JD, Unlu LK, Erdman JW Jr. 1992. Isolation and partial characterizationof $\alpha$ - and $\beta$ carotene-containing carotenoprotein from carrot (Daucus carota L.) root chromoplasts. J Agric Food Chem 40:545-9.

[3] Chau C,Wu S, Lee M. 2007. Physicochemical changes upon micronization process positively improve the intestinal health-enhancement ability of carrot insoluble fibre. Food Chem 104:1569-74.

[4] Negi P.S. and Susanta Kumar Roy (2012) European Food Research and Technology, Volume 212, Issue 4, 445-448

[5] Sharma K., Karki S., Thakur N., and Attri S. (2012) Chemical Composition, Functional Properties and Processing of Carrot-A Review, Journal of Food Science and Technology, Vol. 49, No. 1,. 22-32

[6] Simon, P.W. (2000) Domestication, Historical Development and Modern Breeding of Carrot. Plant Breeding Reviews,Vol. 19,. 157-190.

[7] Upadhyay A (2008). Ph. D. thesis on 'Optimization of carrot pomace powder incorporation on extruded product quality by response surface methodology', Mahatma Gandhi Chitrakoot Gramoday Vishwavidyalys, Satna, Madhya Pradesh, India.

[8] Vasudevan M., and Parle M., (2006) Pharmalogical Evidence for Potential of Daucus carota in the Management of Cognitive Dysfunctions. Biological \& Pharmaceutical Bulletin, Vol 29,. 1154-1161.

[9] http:/www.bakerybazar.com/2010/03/pfa-act-ofindia-and-relevant-standards.html?m=1

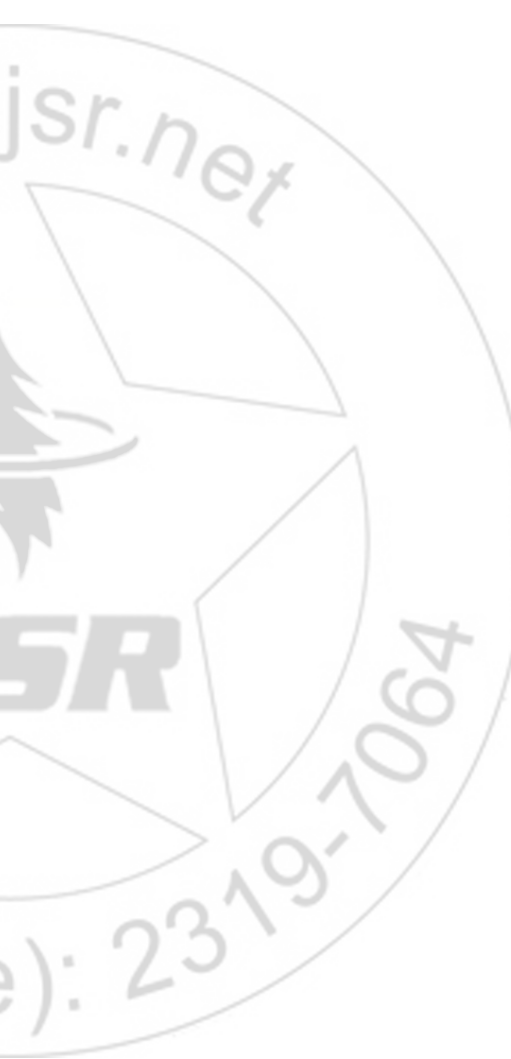

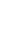

